\title{
Dr Taylor and the Transylvanian Peel
}

$\mathrm{H}$ aving been inspired by the great sleuth, I learned many things; the most important was the ability to observe.

I knew that fortune favours the prepared mind and I determined to pursue the course I thought would favour my destiny.

I was attending in my consulting rooms one afternoon, when a woman entered my office. She had come about her hand, but it was a minor problem and I dealt with it quickly. What fascinated me, however, was her face.

It was an ordinary face - weather-beaten and marked by hardship, although she was young. On both cheeks were large, vivid, red marks. I wondered if this was a form of rosacea or if she had the Wolf syndrome; a syndrome characterized by muscle and joint pains and a skin rash of both cheeks. She was offended and made to leave, but I was able to persuade her to stay, showing my extreme seriousness in pursuing the cause of her unusual condition. I decided this could not be lupus or rosacea because her skin was too smooth, the edges of the rubrous-violaceous marks too defined.

After much hesitation, she told me that she had been applying a substance to her cheeks to smooth them, a substance which was secret and about which she could tell me no more. I did, however, have the opportunity to examine her cheeks from every aspect and angle of light, and used my senses (as was my wont) to determine what she had been applying, for indeed I saw a remarkable smoothness. Where the red colour was, the skin was new, with a soft reflective surface not unlike the surface of undisturbed water. I determined she had arrived in London some three years previously from a village near the Black Sea after a long and arduous voyage. She had been working as a cook and occasional fortune teller. I bid her farewell and thanked her for her indulgence.

Being excited that I had perhaps stumbled upon some new treatment with widespread application, and being at the time one step above professional destitution, I was determined to investigate further. I proceeded to make a lotion containing what I suspected the ingredients to contain. Within two weeks I had made a lotion containing various soothing agents including lanolin and perfumes, honey and, most important, the substance which I felt to be the active agent. Unfortunately, this material exuded a noxious and foreign aroma which I thought had to be disguised to be acceptable to a London clientele. I was able to purchase it from my patient who had her own sources which she would not disclose.

With great trepidation I applied the unguent to a society matron who had consulted me, her own physician being indisposed. Within a month, my waiting room was full and I was dispensing each container for the sum of 10 guineas. Because this was considerably more than my consultation and complete treatment for a difficult case, I was astounded.
I was besieged on all sides by demands to reveal my formula, but I saw no reason to divulge my secret until one day, when the cook returned to my office. She told me she knew that she had been the foundation of my success and suggested a partnership which I could not very well refuse. She said that if we worked together it would be to

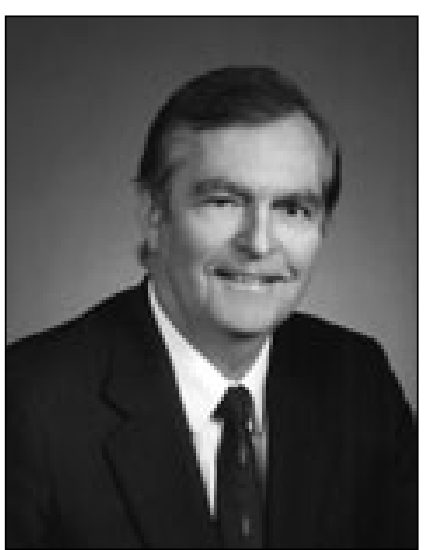

John R Taylor our mutual advantage.

She was a much different person than at our first meeting. Confident and well dressed, she showed every sign of being a woman of means. She told me she wanted to keep our arrangement between the two of us but left no doubt regarding my fate if word became bruited about relating to the origins of my success.

We married the following month and now I am pleased to say, have five healthy and active children who work in the family business when they are not pursing their studies and avocations.

We grow the plant which supplies the secret ingredient at home in our back garden and my wife also uses it in the very popular restaurant she manages.

After many years, I determined that many agents can be used to improve the skin as long as the skin turns red after application and the agent is not so strong as to damage or thin it. I am determined to try Dr Lister's carbolic acid solution soon and think it might have possibilities. My botanical studies have also uncovered a tree leaf from Florida, a desolate marsh in America which according to the natives might have possibilities. I am planning to try galvanism, which might be useful combined with a small roller made of alternating magnetic metals to roll the skin smooth.

With the permission of my wife, and for the betterment of humankind, I can now reveal the active agent and the foundation of our success.

The plant is rather small, about the size of a small lemon and its name is Allium sativum, but you might know it as garlic.

John R Taylor

E-mail jrtaylor@ca.inter.net 